\title{
The History of the Silk Road and Complex in Contemporary China
}

\author{
Ya Feng \\ Shijiazhuang University of Applied Technology, China
}

Keywords: The Silk Road, historical origin, complex of China, construction of economic zone

\begin{abstract}
Well versed in Eurasia and the Silk Road is a great traffic artery in human history, the ancient communication between eastern and western political, economic, cultural and ethnic communication plays a very important role, is the heritage of all mankind, is also a world famous cultural brand. Have the origin and development of the Silk Road, and its historical significance and the current national construction "area along the Silk Road economic belt" a major strategic concept, reproduce the beauty of the ancient Silk Road spirit and contemporary Chinese complex, its historical connotation and deep insight into the important practical significance.
\end{abstract}

\section{Introduction}

In September 2013, Xi Jinping, during a visit to central Asian countries, chairman of the proposed to build economic belt "Silk Road" of the significant strategic concept. This strategic concept mainly includes: strengthen the communication policy, road Unicom, trade flow, currency, and mutually the grand strategic concept is the strategic choice of economic globalization, is also a major measure for promoting the development of the regional economic integrationist the sco regional cooperation by the important transformation of politics, the economy, China's a major breakthrough in the fully open to the west [1]. Strategic vision to point with surface, from line to slice, drew the big regional economic cooperation of the grand blueprint, will make the Eurasian countries closer economic ties and mutual cooperation more in-depth and more vast development space, and is of great realistic significance and far-reaching historical significance. The author tries from the historical sense briefly describes the meaning of the "Silk Road economic belt", to put forward the orientation and the core construction of Xinjiang are studied.

\section{The origin of the Silk Road and its characteristics}

Through Asia, Europe and Africa, the ancient Silk Road along the both countries personnel exchanges and trade logistics transportation route network, is also a cultural exchange between the east and west and bridge, it connects the Eurasian thing north and south, the eastern and western civilizations gathering originative, become a medieval times in different parts of Asia country and nation, economic and cultural communication channel communication between Asia and Europe is not the main channel of different civilizations, human cognition, gradually blend each other, going global, and destiny of the big stage [1].

Look from the vision of China, the Silk Road of generalized is communication in ancient China and the rest of the world transportation route network [1]. The route network have different emphasis in different historical period, both the sea and have replaced. From the western regions to zheng he's seven expeditions to the western seas, land, sea and the Silk Road to China's "four great inventions" and silk, porcelain, tea, etc. Product exports to countries along the way, bringing civilization and friendly, won the praise of people all over the world and love.

On a world scale, generalized the Silk Road is from ancient began to gradually formed, throughout Eurasia, including north Africa and East Africa, the floorboard of the long business trade and cultural exchanges between the lines. Its origin began in the early human natural force driven by remote tribal migration, long distance, and driven by curiosity, exploratory human exploration of the unknown and 
geographic adventure, etc [1]. Archaeological discovery and historical studies confirm that in the western Han dynasty, Zhang qian to the western regions, opened the Silk Road before, between the Eurasian and north Africa have opened more than a similar trade channels.

The origin of the Silk Road. The Eurasian hinterland traffic is almost synchronous with nomadic Tuoma domesticated in this area, scattered in the Eurasian nomadic people reportedly started raising horse around in 41 century BC, the Arab region often use the thirsty and drought tolerant, hungry dromedary in the 11th century BC was used for business travel transport, Bactrian camels in the near future is also used in the business trip [2]. In the hinterland of the grassland region in Asia and Europe, the pre-qin period there is a by many disconnected small-scale trade routes in cohesion and become the "path to grassland".

The Silk Road economic belt historical connotation. In 138 BC, Zhang qian by emperor sent from west Gansu, to big moon people. 13 years, he traveled to numerous of Tangshan between the north and the south and central Asia, west Asia country. During the next 2000 years, numerous merchants and travelers along the tracks, Zhangqian move between countries. Carried the great road east and west is the most glorious ancient civilization, promotes the Eurasia between different countries, different civilizations in merchants, religious, cultural and ethnic communication and integration, for the common development and prosperity of human society has made an outstanding contribution [2]. Today's Silk Road economic belt is formed between China and west Asia countries economic cooperation in a range of geographical area, roughly above the scope of the ancient Silk Road. But today's Silk Road economic belt is based on the ancient Silk Road is mainly composed of high-tech traffic and information technology to form a modern highway, rail and air networks connected to an area, is much larger in scope.

The characteristics of the Silk Road. Network in the long middle ages, the Silk Road of the rise and fall changes often and Eurasian national migration, political landscape changes, background, such as economy, science and technology progress of booms and busts, associated with trade, immigration, travel, war, ethnic conflicts, and religious dissemination activities are closely related. Although the landlocked central Asia prairie road, southwest Silk Road and northeast Asia's coastal sea Silk Road prototype has been formed in the pre-qin period, but behind the rise and fall of history of the Silk Road, land, sea two development and growth of the road is not consistent [2]. In the northwest land by the regime, national factors such as restriction are bigger, southeast sea is greatly influenced by shipbuilding and navigation technology. In China's case, in the time of the unification, the central plains dynasty national strength strong, strong countries, the Silk Road unobstructed, communication flourish;In an era of separate regime, the central plains regime national strength is weak, often around the powerful nation or regime, the land Silk Road often is blocked or even abandoned. Strong in Han and Tang dynasties era, through the west blow the Huns, the Turkic, in the western regions Settings are guard house, road of the Silk Road oasis in northwest China is clear. With the progress of shipbuilding and maritime technology, maritime cost comparative advantage, the sea rise gradually, land gradually decline, Song and Yuan in maritime Silk Road gradually dominated, and instead of the trend, in Ming dynasty, Zheng he's seven trips is maritime Silk Road into a symbol of prosperity [3]. Later, after western expedition, built four khanate, across the Eurasian continent, west and the east sea and land traffic flow, then the prairie road, the path of oasis and the road of the sea into prosperity, the ancient Silk Road or communication is unique in the history of east and west.

\section{The culture complex China's Silk Road}

The Silk Road, is China's economic and cultural exchange between east and west digging channel's historical and cultural heritage of all mankind and the brand, as a result, economic belt "Silk Road" is not accidental, it is both China's emphasis on the Silk Road heritage and inheritance, reflects the reality under the condition of desire to rebrand the human history and culture, also reflects the Eurasian region to reshape the needs of the Silk Road.

The Silk Road is the road to political communication. As early as in the Silk Road digging, the emperor sent Zhang qian to the western regions, the intention is to the west "sun, attack the Huns. 
Zhang Qianceng successively to central Asia;Zhang qian to the western regions again, sent agreement arrived at rest and a body poison (in India), and get all rest angel [3]. Thus, Zhang qian is in itself as a political angel peoples, created the western countries, its political significance is huge. Countries along the Silk Road angel political exchanges, common created the Silk Road.

The Silk Road is the road to economic exchanges. Before opening new routes, the Silk Road is the artery of the economic exchange between east and west. Quantity of products from the western regions via the Silk Road to China mainland, precious stones, jade, bittern, sulfur and other minerals. In the long historical process, the Silk Road on the eastern and western economic development and the improvement in people's life plays an irreplaceable important role [3].

The Silk Road is the way of cultural exchange. The ancient civilizations of east and west, the Silk Road communication of western civilization, Confucian civilization and Islamic civilization, Indian civilization and Russia - are met in the orthodox civilization, communication and communion. A lot of folk art also spread through the Silk Road to the east and the west [3]. Many along the Silk Road culture messenger contacts in China and the western regions and beyond.

Silk Road is the road to national communication. From China's perspective, the Silk Road is cut, the traffic artery of linking east and west in ancient China, reflects the history of ancient Chinese nation to the world;From the perspective of the world, is the ancient "Silk Road" in the western world, on the road to China reflects the procedure of western and Chinese communication; From cultural perspective, the road of Silk Road intersection is one of the world civilization, reflect the cultural exchange between east and west. The Silk Road is a stage in the history of mankind, human communication in the communication, communication and dream, make history [4]. As a result, the Silk Road its great heritage of all mankind is the culture brand of co-creation. Economy today, the construction of the "Silk Road", in fact is the reconstruction of the Silk Road, which is both the needs of the continuation of ancient human dream, it is necessary for the development of the reality in China and the world.

Silk Road economic belt construction in the new period of great ideas for further strengthen China's opening to the outside world is of great practical significance. Construction of the Silk Road economic belt is China comprehensively deepen reform and the need of construction of the socialist cause with Chinese characteristics, is also under the background of globalization to promote the common development of all countries, Europe and Asia the needs of the common prosperity [4]. Put forward in the new period of the Silk Road economic belt of the construction of the great vision, to further promote the inland economy in western China, cultural aspects of each other is of great practical significance.

First, the construction and development of the Silk Road economic belt, can better promote friendly exchanges among the peoples of the world along the Eurasia, different RACES, different nationalities of mutual communication between religion, culture, sharing the peace and common development, to further strengthen exchange and cooperation with countries and regions along the way to bring tangible benefits to the people of all countries along the way and benefits [4].

Second, To further promote the economic development in western China, for the western region's economic development. The new economy the development of the Silk Road, will bring more and more people, logistics, information, money flows, inject vitality to the western region of China economy, further activation in the western region development, promote the all-round exchanges and cooperation, to obtain a bigger development space in western development.

Third, the new Silk Road will become the trade avenue, cultural corridor and the open road. On June 22, 2014 by the, three joint submission of "the Silk Road: the start and Tangshan mountain corridor network" to declare the world cultural heritage [5]. Further highlight it reflected the new period along the Silk Road economic belt construction of regions and countries that have significant influence on the world economy and culture, especially improve further exchanges between China and Asia, Arab countries, communication, and strengthen the communication policy, deepen pragmatic cooperation with the greater the power, which has a great realistic significance.

The China's connotation and meaning of Silk Road economic belt on the development. China put forward the construction of economic zone "Silk Road", is actually on the Silk Road history 
cultural heritage and brand to regain and reshaping, is for the development of the inland and coastal areas to two or more things and balance, is the eastern, central and western region development coordination, and emphasis on the western frontier growing non-traditional security [5].

Economic belt on the "Silk Road" build for the meaning of the Chinese academic circle has talked about a lot of things, such as expand the strategic development space, to ensure the safety of energy resources strategy, enhance China's voice in the international iron ore market, accelerate the economic transformation and upgrading, and industrial structure adjustment, conducive to energy conservation and emissions reduction and environmental protection, conducive to China's regional economic coordinated development and conducive to national defense security and social stability, etc [5]. Economic belt "Silk Road" to east Asia economic circle and the Western Europe developed economic circle, at the same time, through the middle of the economic depression, but also can form new economic growth pole;Inside China can string up the east coast of the pearl river economic circle, the Yangtze river estuary economic circle and economic circle, coordination in east development in China. Economic belt "Silk Road" of the construction will influence the global economic landscape, for the world economy big development and cooperation, for China's west strategy, benefit for promoting China's industrial upgrading, driving along the country's development. These are very reasonable, is a good outline for the future.

The Silk Road heritage inheritance. China's geographical endowment is both continents and oceans, is a country with a continental and oceanic [6]. In terms of continental China back on the world's largest Eurasian continent, the deep interior space, the ancient Eurasian inland more great impact on Chinese history society, whether in Chinese politics, society, culture and nation, were leaving a trail of long effect and deep inland, in a sense, the Silk Road was vividly reflects the Eurasian inland relations with China, is the crystallization of the interaction of both. In terms of sea, yellow sea of China, East China Sea and South China Sea has access to the vast Pacific Ocean and the Indian Ocean.

"The Silk Road economic belt" is on the Silk Road the reshaping of the brand. The Silk Road, with its long history and great contribution in humans, has been a recognized history between east and west culture brand and famous brand. Most of countries along the Silk Road deep in the inland, to rebuild its long-awaited glory [6]. And the revolutionary change of modern traffic, communication, provides a new Silk Road to restore. To reshape the Silk Road there will be two prominent features, it is a new Silk Road no doubt will be beyond the plane in the history of a single feature, presents a three-dimensional and compound, such as the Eurasian inland air lines, high-speed rail and rail line, highway and highway line, deep underground oil and gas pipeline route, and vertical and horizontal with information network line construction;The second is the modern Silk Road will greatly expand the scope of space, it will be centered on inland Asian area, east to the Pacific and the Atlantic ocean on the west, south and the Indian Ocean, north across Russia, is by no means simply intertwined with the traditional concept of the Silk Road [6]. Modern Silk Road construction present a leap in quality and quantity, its connotation is already beyond the traditional connotation of the Silk Road, become the largest communication network in Eurasia, therefore, the Silk Road to reshape the impact of also will be a revolutionary.

The Silk Road economic belt is to two or morethings and balance in the development of inland and coastal areas. "Silk Road economic belt" construction will lead to regional big open, big development, communication, development and integration, political mutual trust, and security interdependence between national, economy, culture promote each other mutual infiltration and personnel flow, will become the main shaft and trends;Boundary functions and common management mode and operation will be looking forward. Visible, the construction of the "Silk Road economic belt" openness, initiative and participation and regional integration, are all unprecedented [6].

Carry forward the spirit of the Silk Road to realize win-win cooperation. Silk Road spirit is connotation. China President Xi Jinping mentioned: "one thousand years, the Silk Road of peaceful cooperation, open inclusive, each other mutual learning, mutual benefit and win-win spirit new generation [5]. Therefore, we can see the 16-character as all join and share the spirit of the Silk Road. 
The new Silk Road is a road of the peaceful development of win-win. It is an open road, road, the road of peaceful development, the road to a win-win, safe road, the road of integration.

\section{Conclusion}

Now, in the construction of modern Silk Road economic belt, hand in photograph reflect modern transportation and ancient culture. In modern economic and trade development period, always flowing blood relation of the ancient Chinese excellent traditional culture, this is the Chinese nation since ancient times, solidarity and mutual trust, equality and mutual benefit, mutual learning, cooperation and win-win "spirit of the Silk Road", as long as we are down-to-earth, sincere cooperation, and Eurasian countries work together, we will be able to create a more beautiful, civilized and harmonious China, let the spirit of "Silk Road" forever vigor and vitality, has become China's economic openness to trade in the development and construction of a bright scenery.

\section{References}

[1] T. D. Chen, "The silk road economic belt" bridgehead, The contemporary Shaanxi, 2013, vol.12, pp. 14-17.

[2] V. M. Lin, Ten five lectures the archaeology of the Silk Road, Beijing: Peking University press, 2007, vol. 5, pp. 4-8.

[3] X. P. Zhu, China - central Asia new Silk Road economic development belt, northeast Asia BBS, 2013, vol. 2, pp. 18-23.

[4] Y. Y. Huang, About the construction of the new Asia-Europe continental bridge economic and cultural coordinate with east's Suggestions to the development of the Midwest, Report at the Chinese academy of social sciences, 2011, vol. 12, pp. 31-35.

[5] M. Y. Wang, The structure of the Silk Road economic belt and the strategic significance, journal ofTianshui administration institute, 2013, vol.6, pp. 43-46.

[6] A. Y. Hu, Connotation, strategic positioning and implementation path of the silk road economic belt, Journal of Xinjiang normal university, 2014, vol. 2, pp. 57-61. 